Research Article

\title{
Experimental Study of the Ultrasonic Vibration-Assisted Abrasive Waterjet Micromachining the Quartz Glass
}

\author{
Rongguo Hou (D), Tao Wang, Zhe Lv, and Yuanyong Liu \\ School of Mechanical Engineering, Shandong University of Technology, Zibo 255000, China \\ Correspondence should be addressed to Rongguo Hou; hourongguo212@163.com
}

Received 29 June 2017; Revised 15 November 2017; Accepted 3 December 2017; Published 5 February 2018

Academic Editor: Fernando Lusquiños

Copyright ( 2018 Rongguo Hou et al. This is an open access article distributed under the Creative Commons Attribution License, which permits unrestricted use, distribution, and reproduction in any medium, provided the original work is properly cited.

\begin{abstract}
The ultrasonic vibration is used to enhance the capability of the abrasive water micromachining glass. And, the ultrasonic vibration is activated on the abrasive waterjet nozzle. The quality of the flow is improved, and the velocity of the abrasive is increased because of the addition of the ultrasonic energy. The relevant experimental results indicate that the erosion depth and the material volume removal of the glass are obviously increased when ultrasonic vibration is working. As for the influence of process parameters on the material removal of the glass such as vibration amplitude, system pressure, distance of the standoff, and abrasive size, the experimental results indicate that the system pressure and vibration contribute greatly to the glass material removal. Also, the erosion depth and the volume of material removal are increased with the increase in the vibration amplitude and system pressure. There are some uplifts found at the edge of erosion pit. Then, it can be inferred that the plastic method is an important material removal method during the machining process of ultrasonic vibration-assisted abrasive waterjet.
\end{abstract}

\section{Introduction}

The quartz glass is widely used in many fields such as military, aeronautics, medical, measurement instruction, and the light industry $[1,2]$ Because it is a typical brittle and hardto-machine material, the conventional machining process cannot be successfully applied in the glass product production, while abrasive waterjet (AWJ) technology has a great advantage in the production of the glass products, because it has no heat deformation, high machining efficiency, and high accuracy, especially in the glass micromachining process [3-5]. In order to increase the efficiency of the abrasive waterjet machining glass, the pulsed waterjet has been a research issue, for the reason that it could obtain a greater removal of target material by generating water-hammer effect, for example, Vijay et al. [6], Chahine et al. [7], and Ghadi et al. [8] have introduced a kind of pulsed waterjet using an ultrasonic vibration on the nozzle, the jet's energy is pretty low, and the amount of material removal is increased greatly. Zelenak et al. [9] have obtained visualization of pulsating and continuous waterjets by using the PIV processing algorithms, with an aim to obtain waterjet geometry and velocity distribution. Lehocka et al. $[10,11]$ have studied changes in surface layer and strengthening in subsurface layer of the copper CW004A and brass CW614N machined by pulsed waterjet. Their research result indicates that the pulse waterjet has a great advantage contrasted to the continuity waterjet. With an aim to produce a high-quality pulsed waterjet, Lv [12] and Zhang [13] have used the ultrasonic vibration to activate on the workpiece; their experiments indicate that the material removal rate and the erosion depth of the ceramic are increased when the ultrasonic vibration is working. Vijay et al. [6] and Foldyna et al. $[14,15]$ have used the ultrasonic vibration which is working on the waterjet nozzle to produce the pulse waterjet; their experiments indicate that the material removal of the metal and marble has been increasing greatly. Although a considerable amount of research has been carried out on ultrasonic vibration-assisted waterjet technology, there is little literature about experimental investigation on the micromachinery of the glass by the ultrasonic vibration-assisted abrasive waterjet. With an aim to investigate the effect of the ultrasonic variations on the micromachinery of the glass by abrasive waterjet, a series of experiments have been carried 


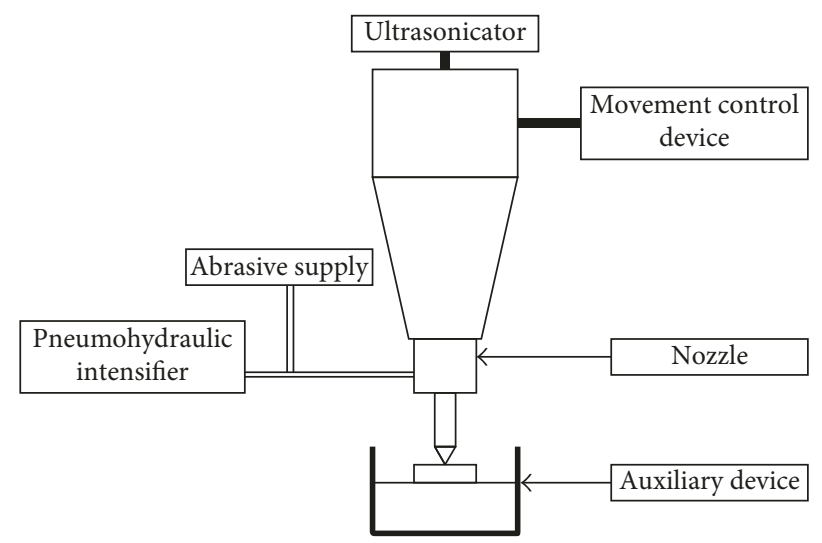

FIGURE 1: The diagram of ultrasonic vibration-assisted abrasive waterjet machining.

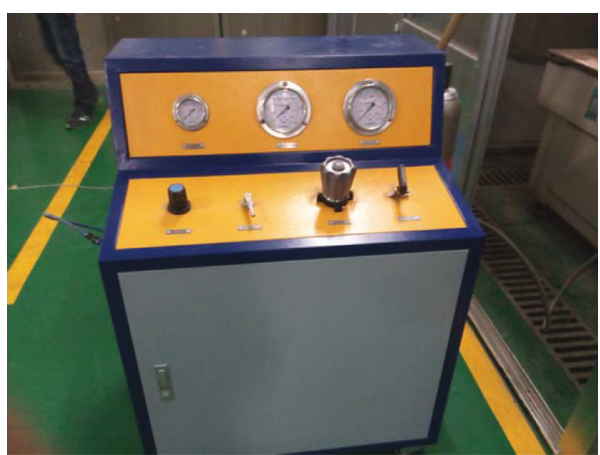

(a)

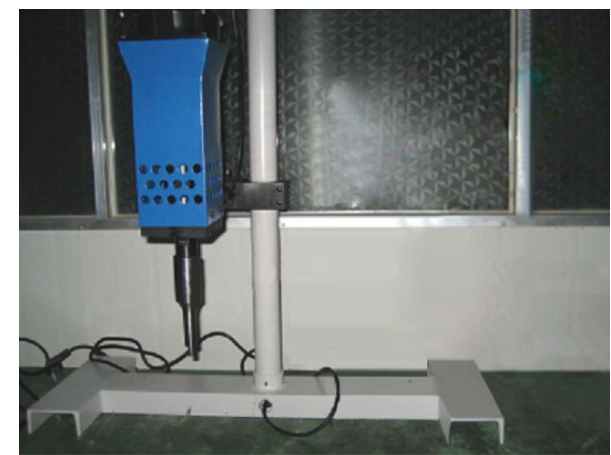

(b)

FIgUre 2: (a) The pneumohydraulic intensifier. (b) The device of ultrasonic vibration-aided abrasive waterjet.

TABle 1: The value of the experimental parameters.

\begin{tabular}{lcccccc}
\hline $\begin{array}{l}\text { System } \\
\text { pressure }(\mathrm{MPa})\end{array}$ & $\begin{array}{c}\text { Nozzle } \\
\text { diameter }(\mathrm{mm})\end{array}$ & $\begin{array}{c}\text { Distance } \\
(\mathrm{mm})\end{array}$ & $\begin{array}{c}\text { Abrasive supply } \\
\text { rate }(\mathrm{mg} / \mathrm{s})\end{array}$ & $\begin{array}{c}\text { Ultrasonic } \\
\text { frequency }(\mathrm{kHz})\end{array}$ & $\begin{array}{c}\text { Amplitude of ultrasonic } \\
\text { vibration }(\mu \mathrm{m})\end{array}$ & $\begin{array}{c}\text { Abrasive } \\
\text { mesh }(\#)\end{array}$ \\
\hline $5-25$ & 1 & $3-7$ & 2.5 & 20 & 10,20 , and 30 & SiC \\
\hline
\end{tabular}

out, and the effect of the process parameters, such as vibration amplitude, the system pressure, the distance of standoff, and the abrasive diameter, has been considered on the glass material removal vibration amplitude.

\section{The Experimental Setup}

The experimental diagram of ultrasonic vibration-assisted abrasive waterjet micromachining glass is shown in Figure 1. It indicates that the ultrasonic vibration is acting on the abrasive waterjet nozzle.

The experimental equipment of ultrasonic vibrationassisted abrasive waterjet is self-developed, and it is used in the process of micromachining the quartz glass. As shown in Figure 2(a), the abrasive waterjet system could provide pressure within $0-70 \mathrm{MPa}$, the system pressure of waterjet in this study is between 5 and $25 \mathrm{MPa}$, it is pretty low to meet the requirment of micromachining the ceramics materials, and the ultrasonic vibration process of the micromachining is used to decrease the pressure in the experiment. As shown in Figure 2(b), the ultrasonic auxiliary device provides the vibration with a frequency of $20 \mathrm{kHz}$, its vibration amplitude is about $20 \mu \mathrm{m}$, and the vibration amplitude could vary by changing the ultrasonic horn. The abrasive is drawn into the nozzle by the compressed air, and the abrasive nozzle is connected with the ultrasonic horn. The waterjet nozzle diameter is $1 \mathrm{~mm}$, the standoff distance is within $3-7 \mathrm{~mm}$, and the abrasive supply rate is $2.5 \mathrm{mg} / \mathrm{s}$.

The experimental parameters are as shown in Table 1. They include the system pressure, nozzle diameter, abrasive supply rate, standoff distance, the frequency and amplitude of ultrasonic vibration, and the property of abrasive. The mechanical properties of quartz glass are as shown in Table 2. The erosion surface morphology of experimental samples is observed, and the experimental data are analyzed with the help of the instrument of Keyence 3D Laser Shape Measurement (VK200). 
TABLE 2: Mechanical properties of quartz glass.

\begin{tabular}{lcccccc}
\hline $\begin{array}{l}\text { Density } \\
\left(10^{3} \mathrm{~kg} / \mathrm{m}^{3}\right)\end{array}$ & $\begin{array}{c}\text { Hardness } \\
(\text { morse })\end{array}$ & $\begin{array}{c}\text { Microhardness } \\
(\mathrm{HV})\end{array}$ & $\begin{array}{c}\text { Tensile strength } \\
(\mathrm{MPa})\end{array}$ & $\begin{array}{c}\text { Compressive strength } \\
(\mathrm{MPa})\end{array}$ & $\begin{array}{c}\text { Young's module } \\
(\mathrm{GPa})\end{array}$ & $\begin{array}{c}\text { Poisson's } \\
\text { ratio }\end{array}$ \\
\hline 2.2 & $5.5-6.5$ & $8000-9000$ & 50 & 1100 & 72 & 0.17 \\
\hline
\end{tabular}

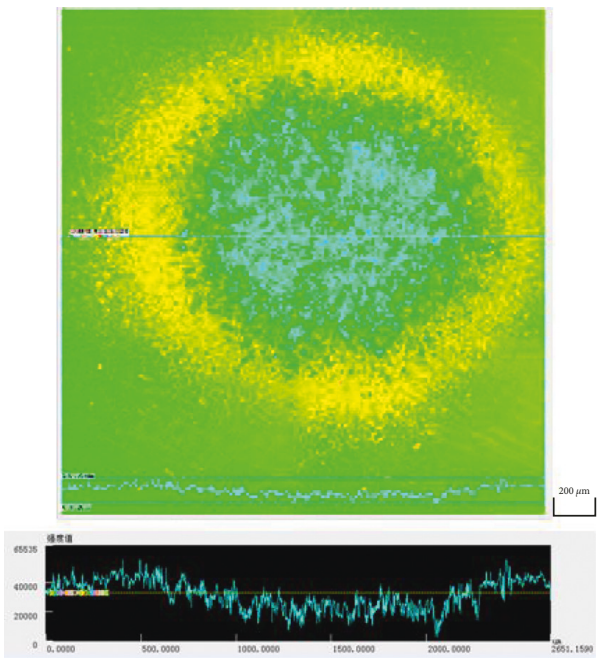

(a)

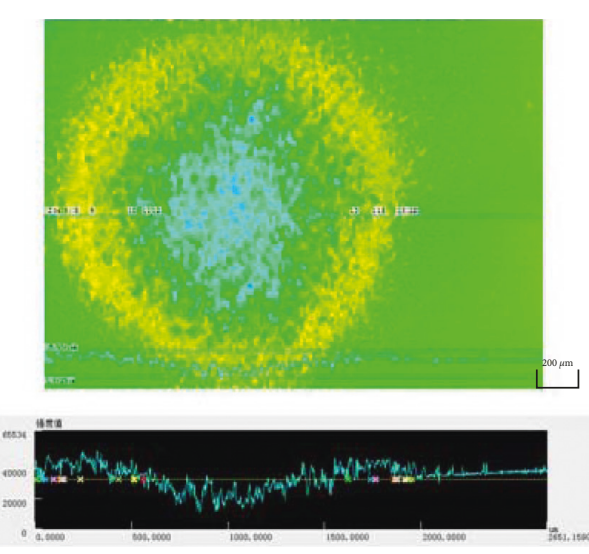

(b)

FIgURE 3: The erosion surface morphology of quartz glass. (a) No vibration. (b) With vibration.

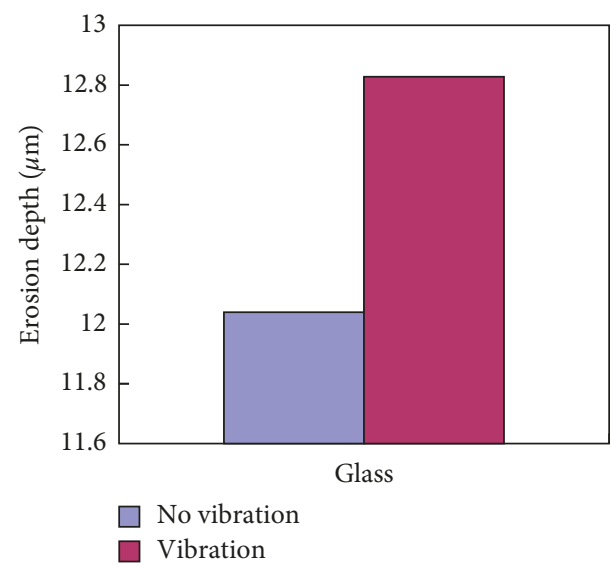

(a)

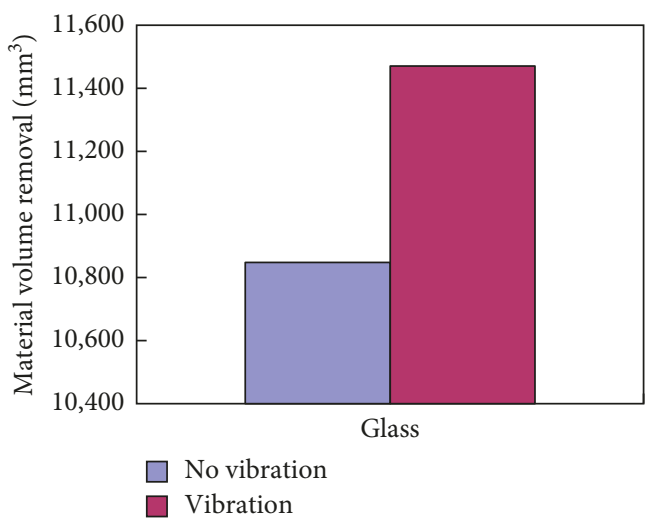

(b)

Figure 4: The erosion depth (a) and material removal amount (b) of workpiece.

\section{The Experimental Result and Its Discussion}

Figures 3(a) and 3(b) show the erosion surface morphology of experimental sample both with and without the ultrasonic vibration. Figure 3(a) indicates that there are some pits on the surface of the glass which is machined by abrasive waterjet; the diameter of the pit is about $1.5 \mathrm{~mm}$, the maximum depth of the pit is about $8.2 \mu \mathrm{m}$, and the plastic deformation zone is around the erosion pit. Figure $3(\mathrm{~b})$ shows that the diameter of the erosion pit increases, and the maximum depth of the erosion pit becomes deep when the ultrasonic vibration is applied.
Figures 4(a) and 4(b) show the erosion depth and material removal amount with and without the ultrasonic vibration. Figures 4(a) and 4(b) indicate that the erosion depth and the material removal amount increase obviously when the ultrasonic vibration is applied, especially the material removal amount increases greatly, while the horizontal width of the erosion area increases slightly. Therefore, it could be inferred that the ultrasonic vibration improves the processing capacity of the abrasive waterjet.

Figures 5(a)-5(c) show the erosion surface morphology of experimental sample with different amplitudes. Their changing tendency could be inferred from Figure 6. 


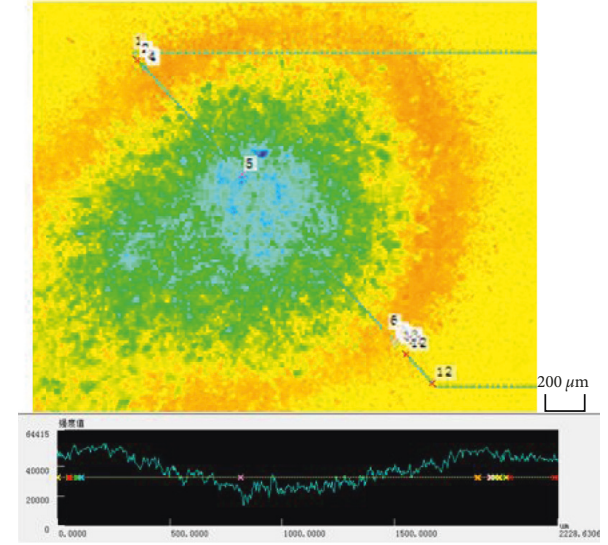

(a)

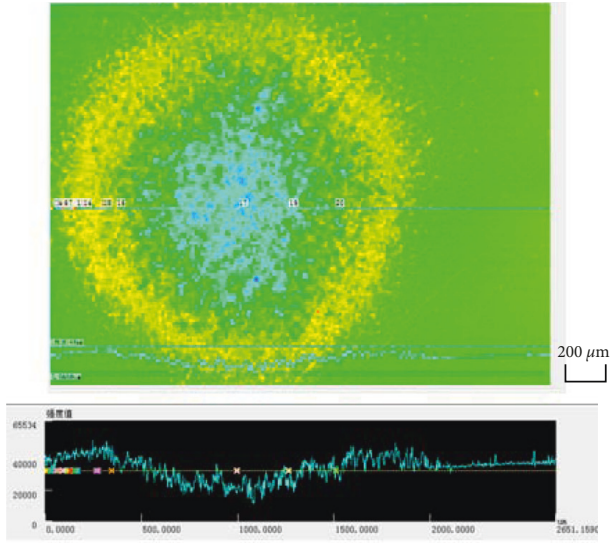

(b)

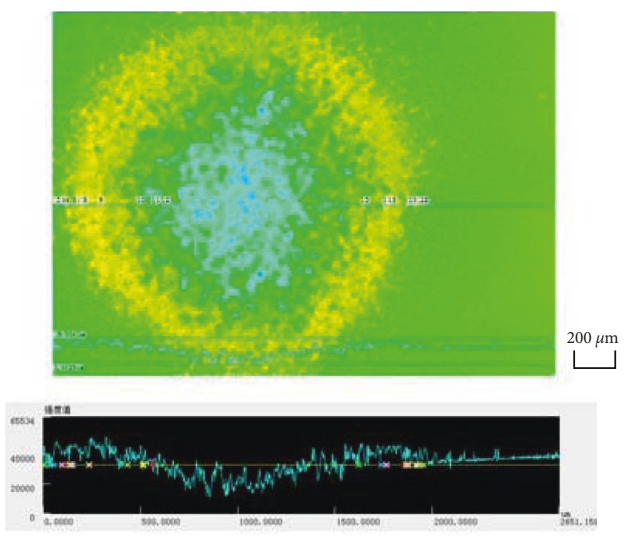

(c)

Figure 5: The influence of amplitude on erosion surface morphology of quartz glass. (a) $a=10 \mu \mathrm{m}$. (b) $a=17 \mu \mathrm{m}$. (c) $a=22 \mu \mathrm{m}$.

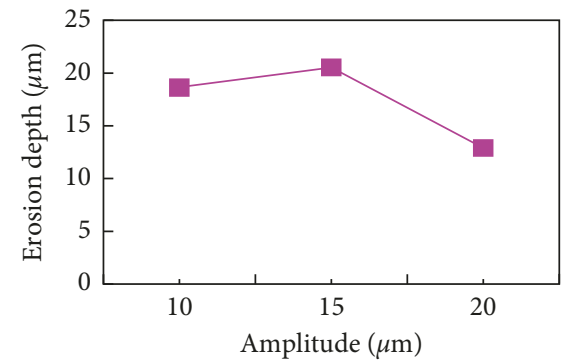

(a)

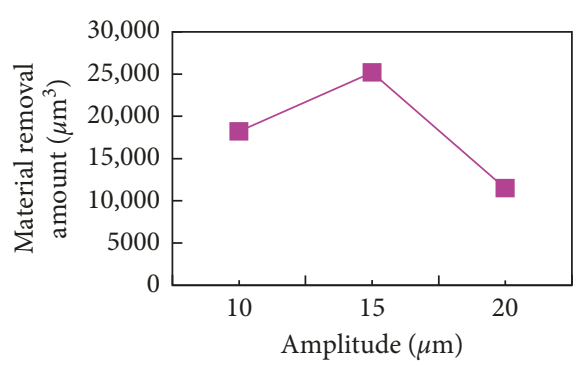

(b)

Figure 6: The influence of amplitude on erosion depth (a) and material removal amount (b) of workpiece.

Figures 6(a) and 6(b) show, respectively, the influence of amplitude on erosion depth and material removal amount of the quartz glass. They indicate that there is an optimized value of the amplitude, such as the $17 \mu \mathrm{m}$, to gain the largest erosion depth and the greatest material removal amount. It is mainly because with an increase of amplitude, the disturbance degree of the waterjet will become large and the abrasive inside the waterjet will be activated; thus, the energy of the waterjet increases, the abrasive is accelerated, and the impact force is obtained. Then, the deformation of the material removal amount and the erosion depth increases, but the direction of abrasive movement could be changed if the waterjet undergoes a serious disturbance. Thus, the material removal amount and the erosion depth will decrease.

Figures 7(a)-7(e) show the erosion surface morphology of the quartz glass under the condition that the waterjet pressures are $5 \mathrm{MPa}, 10 \mathrm{MPa}, 15 \mathrm{MPa}, 20 \mathrm{MPa}$, and $25 \mathrm{MPa}$, respectively, the abrasive grain is \#320, the abrasive supply rate is $2.5 \mathrm{mg} / \mathrm{s}$, and the processing time is $8 \mathrm{~s}$. Figures $8(\mathrm{a})$ and $8(\mathrm{~b})$ show the influence of waterjet pressure on erosion depth and material removal amount. Figure 8(a) indicates that the erosion depth becomes 


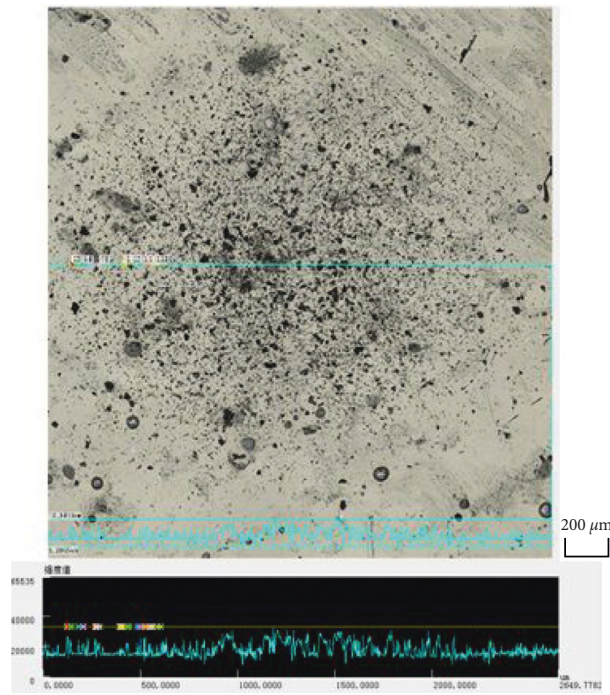

(a)

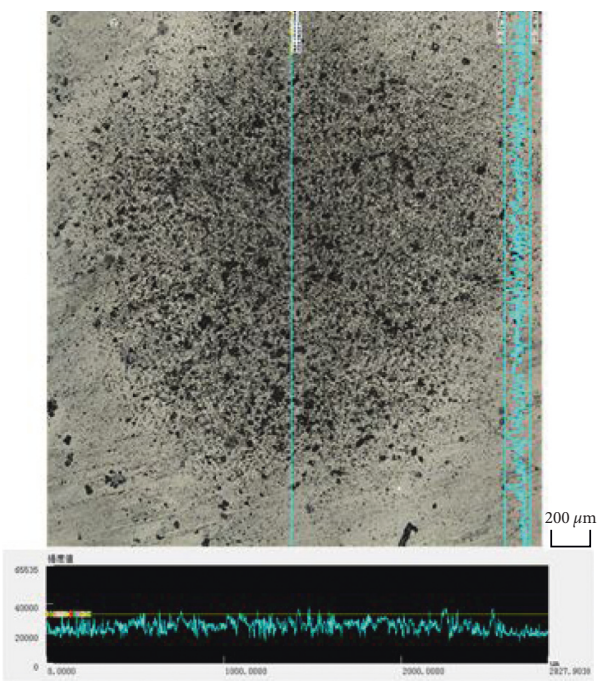

(c)

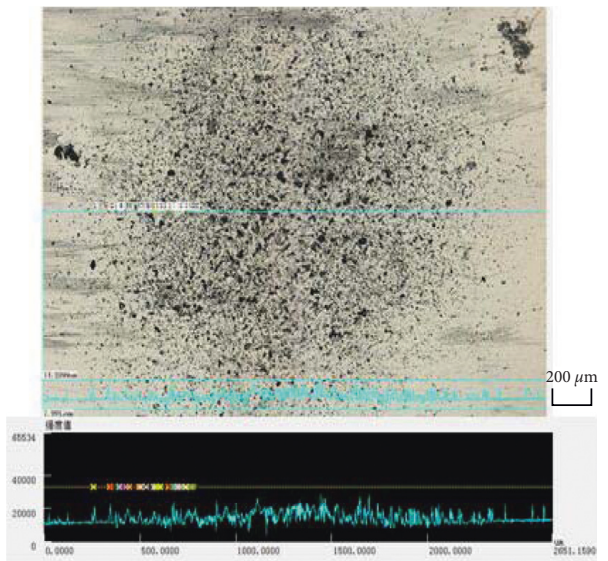

(b)

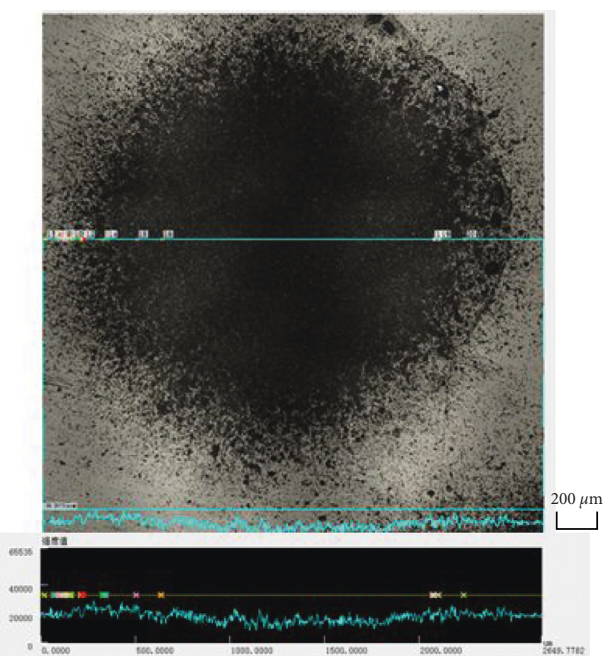

(d)

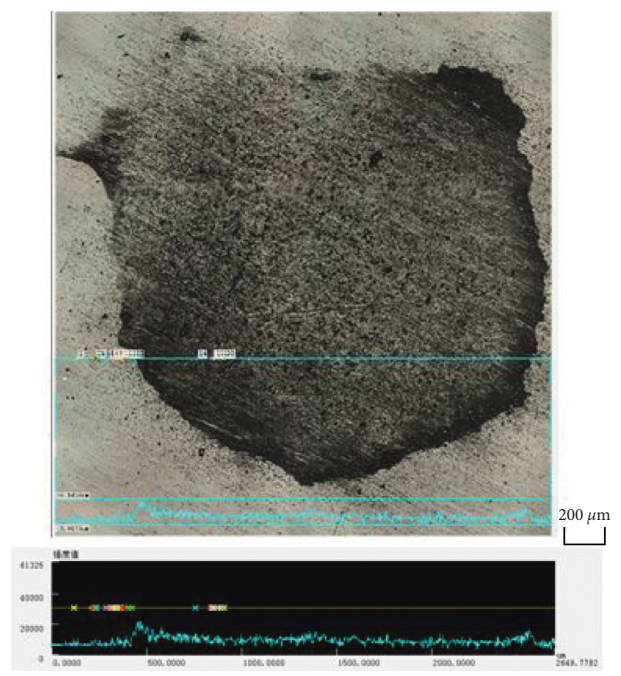

(e)

FIgURE 7: The influence of waterjet pressure on erosion surface morphology of quartz glass $(a=22 \mu \mathrm{m}$ and $B=5 \mathrm{~mm})$. (a) $P_{s}=5 \mathrm{MPa}$. (b) $P_{s}=10 \mathrm{MPa}$. (c) $P_{s}=15 \mathrm{MPa}$. (d) $P_{s}=20 \mathrm{MPa}$. (e) $P_{s}=25 \mathrm{MPa}$. 


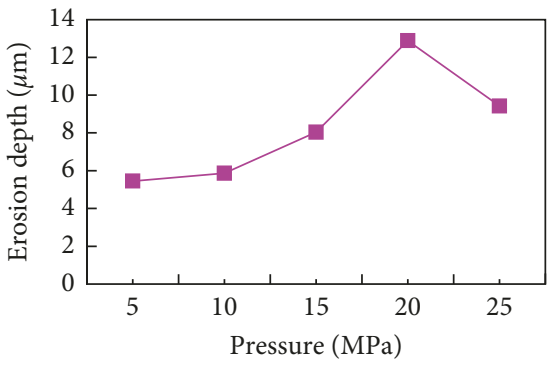

(a)

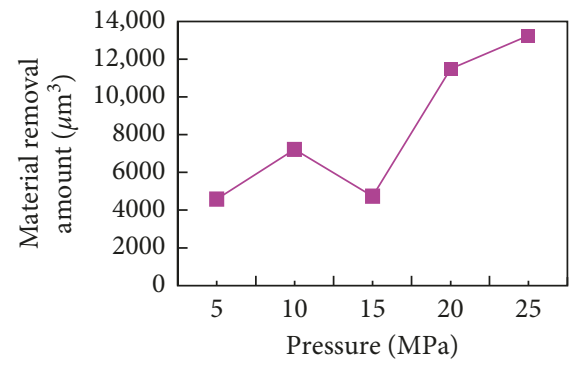

(b)

Figure 8: The influence of waterjet pressure on (a) erosion depth and (b) material removal amount.

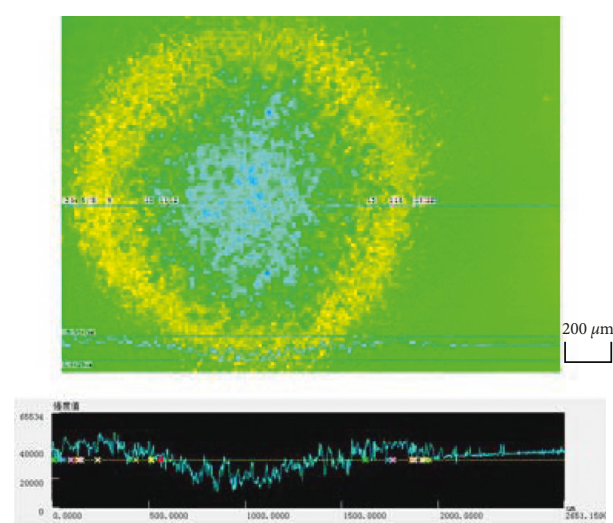

(a)

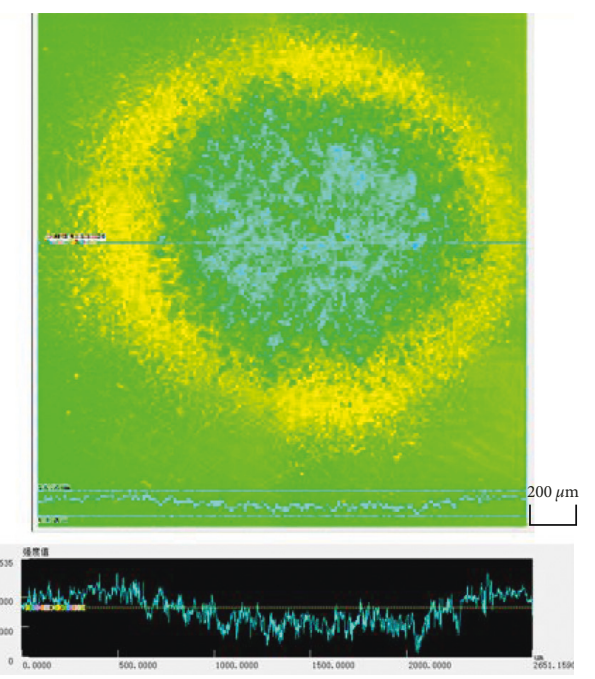

(b)

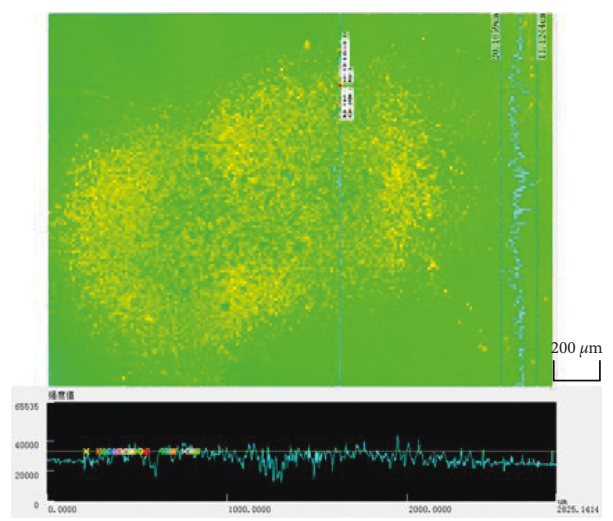

(c)

Figure 9: The influence of the standoff distance on erosion surface morphology of quartz glass $\left(P_{s}=20 \mathrm{MPa}, a=22 \mu \mathrm{m}\right)$. (a) $B=3 \mathrm{~mm}$. (b) $B=5 \mathrm{~mm}$. (c) $B=7 \mathrm{~mm}$.

deeper with an increase of waterjet pressure before $20 \mathrm{MPa}$, the erosion depth is decreased when the waterjet pressure exceeds the $20 \mathrm{Mpa}$. Also, as shown in Figure 8(b), the material removal amount becomes greater with an increase in waterjet pressure. The small waterjet pressure could lead to the low normal component of impact force. Meanwhile, there are only some individual high points on the workpiece surface where the shearing erosion took place for the reason that there is a high surface roughness of the experimental sample.

Figures 9(a)-9(c) show the influence of the standoff distance on erosion surface morphology of the experimental sample. Figures 10(a) and 10(b) show the influence of the standoff distance on erosion depth and material removal amount. It indicates that the erosion depth and the material removal amount decrease with an increase of the standoff 


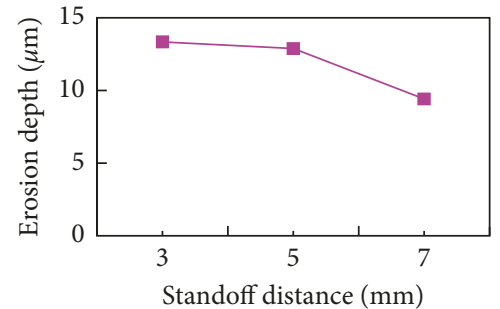

(a)

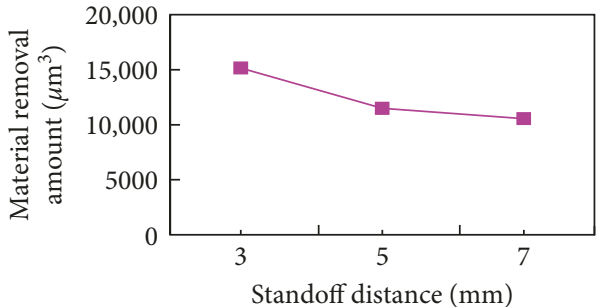

(b)

FIGURE 10: The influence of the standoff distance on (a) erosion depth and (b) material removal amount.

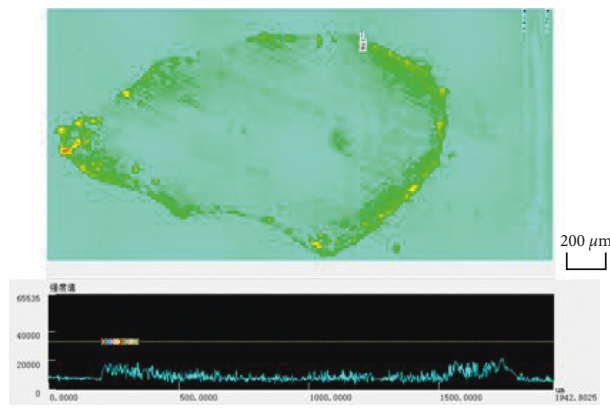

(a)
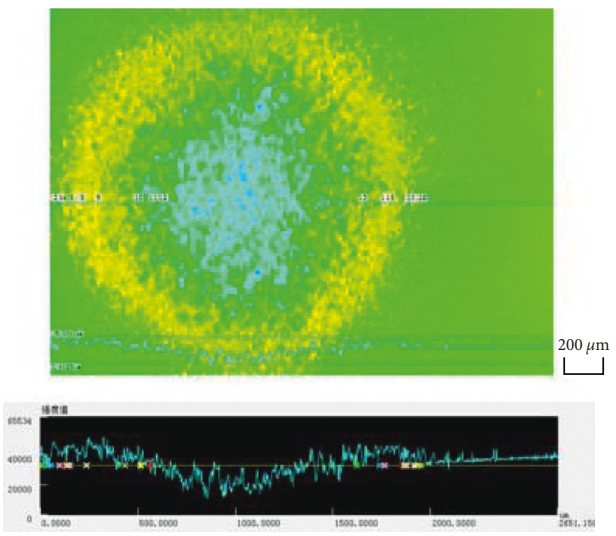

(b)

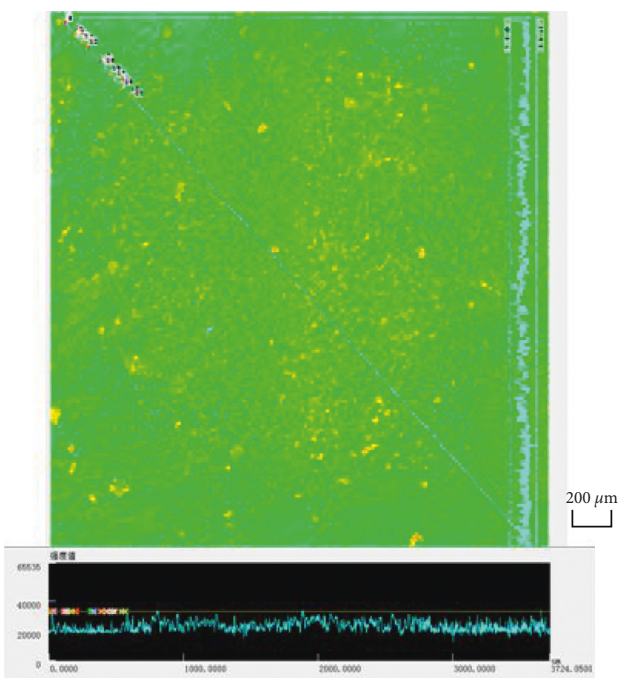

(c)

Figure 11: The influence of abrasive grain on erosion surface morphology of quartz glass $\left(P_{s}=20 \mathrm{MPa}, a=22 \mu \mathrm{m}\right.$, and $\left.B=5 \mathrm{~mm}\right)$. (a) $\# 280$. (b) \#320. (c) \#400.

distance. The reason is that the diffusion degree increases when the standoff distance increases, and the energy and the speed decreases so that the deformation amount, the erosion depth, and the horizontal erosion area are decreased.

Figures 11(a)-11(c) show the erosion surface morphology of the experimental sample under the condition that the abrasive grains are $\# 280, \# 320$, and \#400, respectively, the waterjet pressure is $20 \mathrm{MPa}$, the target distance is $5 \mathrm{~mm}$, the abrasive supply rate is $2.5 \mathrm{mg} / \mathrm{s}$, and the processing time is $8 \mathrm{~s}$. Figures 12(a) and 12(b) show the influence of abrasive size on the erosion depth and material removal amount. They indicate that the erosion depth and the material removal amount increase firstly and then decrease subsequently with an increase of abrasive size. There is an optimized value of the abrasive size (\#320) to gain the largest erosion depth and the greatest material removal amount. 


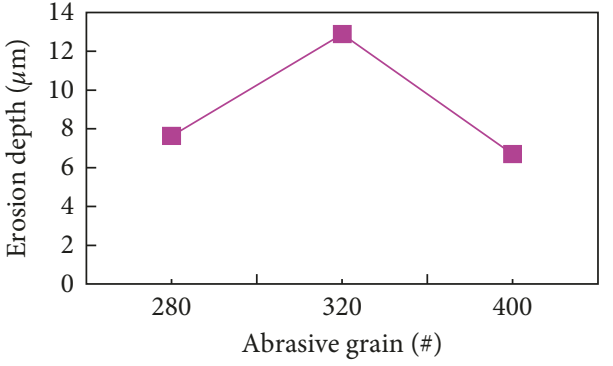

(a)

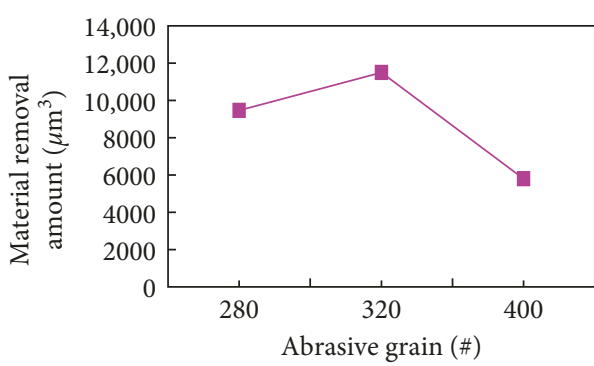

(b)

Figure 12: The influence of abrasive grain on (a) erosion depth and (b) material removal amount.

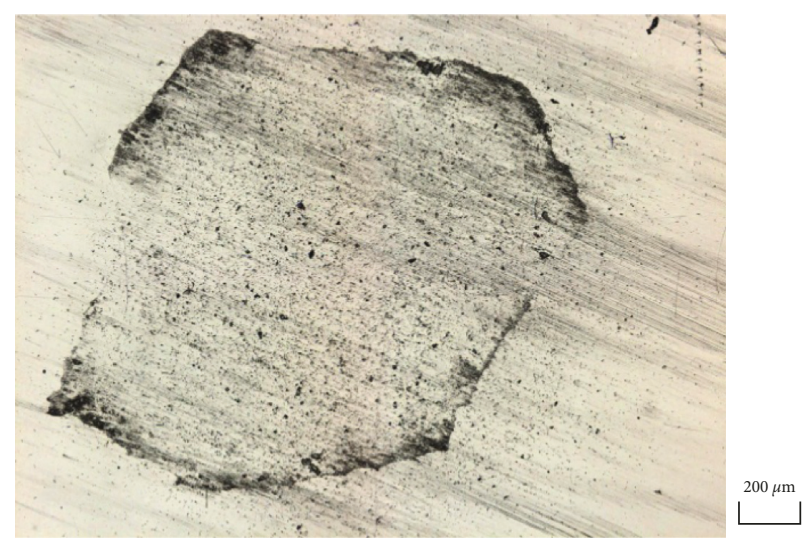

(a)

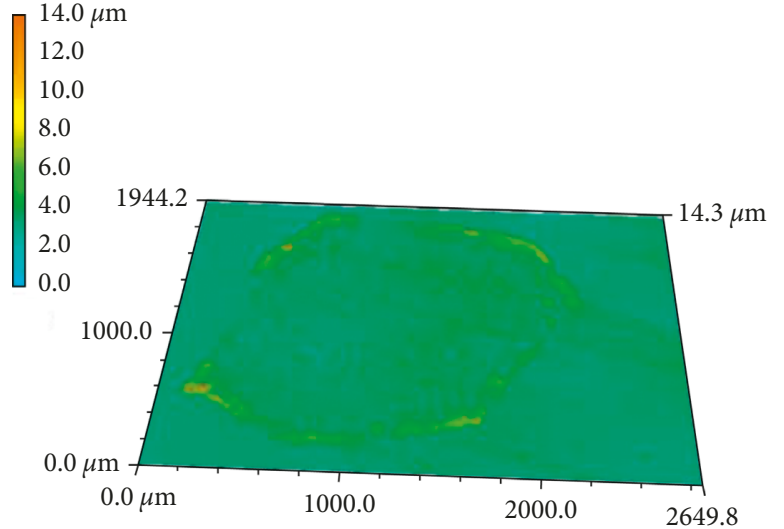

(b)

FIGURE 13: The erosion surface morphology of quartz glass by using the fragile removal method ( $P_{s}=25 \mathrm{MPa}, a=22 \mu \mathrm{m}$, and $\left.B=3 \mathrm{~mm}\right)$. (a) Plane view. (b) $3 \mathrm{D}$ view.

The kinetic energy and the erosion ability are very great when the abrasive is mixed with waterjet. The small abrasive grain which the energy acts on could easily obtain the high velocity of the individual particle. Thus, the material removal amount and the erosion depth are also very large. Therefore, the smaller the abrasive grain is, the deeper the erosion depth becomes and the more brittle the removal method gets.

\section{The Erosion Mechanism Analysis}

Figures 13(a) and 13(b) show the erosion surface morphology of quartz glass. They indicate that there is brittle fracture, crushing, and shedding on the surface of quartz glass, for the reason that the fracture of quartz glass is smaller, whereas there is also a big crack zone on the surface of quartz glass, which is mainly due to a large number of microcracks and surface defects existing on the surface of brittle materials. The experiment result also shows that the plastic deformation is very small at the edge of erosion pit, and it is rugged obviously at the bottom of erosion pit. But, there are still some uplifts which are found at the edge of erosion pit. It is indicated that the plastic method is also the same as the material removal method during the machining process of ultrasonic vibration-assisted abrasive waterjet, just as shown in Figure 14.

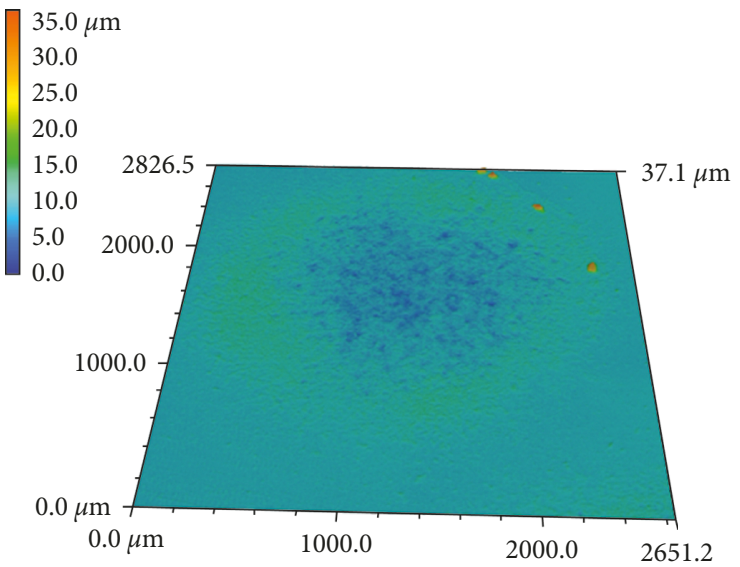

FIGURE 14: The erosion surface morphology of quartz glass by using the plastic removal method $\left(P_{s}=20 \mathrm{MPa}, a=22 \mu \mathrm{m}\right.$, and $B=5 \mathrm{~mm}$ ).

\section{Conclusions}

The experimental study of the ultrasonic vibration-assisted abrasive waterjet micromachining the glass is performed. The depth of the erosion and the amount of material volume removal are obviously increased when the ultrasonic vibration is applied. The efficiency of the abrasive waterjet is 
obviously increased. The moving behavior of the abrasive is changed because the waterjet flow field is seriously disturbed when ultrasonic vibration is applied, and the positive or negative rule will play on the abrasive movement which is decided by the property of the waterjet. Meanwhile, the erosion mechanism is also changed when the ultrasonic vibration is applied, because the plastic deformation becomes an important removal method as for the glass. This is helpful to gain a high-quality surface of the glass products, and this technology could be used in glass surface polishing.

\section{Conflicts of Interest}

The authors declare that there are no conflicts of interest regarding the publication of this paper.

\section{Acknowledgments}

This work is financially supported by the National Natural Science Foundation of China (51405274) and the Program for the Young Development of Shandong University of Technology.

\section{References}

[1] O. Horiuchi, J. Ikeno, H. Shibutani, H. Suzuki, and Y. Mizukami, "Nano-abrasion machining of brittle materials and its application to corrective figuring," Procision Engineering, vol. 31, no. 1, pp. 47-54, 2007.

[2] M. Zhou, B. Ngoi, M. N. Yusoff, and X. J. Wang, "Tool wear and surface finish in diamond cutting of optical glass," Journal of Materials Processing Technology, vol. 174, no. 1-3, pp. 29-33, 2006.

[3] M. Hashish, "Pressure effects in abrasive water jet (AWJ) machining," Journal of Engineering Materials and Technology, vol. 111, no. 3, pp. 221-228, 1989.

[4] Z. W. Liu, Study on Removal Mechanism of Hard Brittle Materials and Premix Micro Abrasive Waterjet Polishing Technology, Shandong University, Jinan, China, 2011.

[5] J. Wang, "Particle velocity models for ultra high pressure abrasive waterjets," Journal of Materials Processing Technology, vol. 209, no. 9, pp. 4573-4577, 2009.

[6] M. M. Vijay, J. Foldyna, and J. Remisz, "Ultrasonic modulation of high-speed waterjets," in Proceeding of International Conference on Geomechanics, pp. 327-332, Ostrava, Czech Republic, September 1993.

[7] G. L. Chahine, K. M. Kalumuck, and G. S. Frederick, "The use of self-resonating cavitating water jets for rock cutting," in Proceedings of the 8th American Water Jet Conference, Houston, TX, USA, August 1995.

[8] S. Ghadi, K. Esmailpour, S. M. Hosseinalipour, and A. Mujumdar, "Experimental study of formation and development of coherent vortical structures in pulsed turbulent impinging jet," Experimental Thermal and Fluid Science, vol. 74, pp. 382-389, 2016.

[9] M. Zelenak, J. Foldyna, J. Scucka, S. Hloch, and Z. Riha, "Visualisation and measurement of high-speed pulsating and continuous water jets," Measurement, vol. 72, pp. 1-8, 2015.

[10] D. Lehocka, D. Klichova, J. Foldyna et al., "Comparison of the influence of acoustically enhanced pulsating water jet on selected surface integrity characteristics of CW004A copper and CW614N brass," Measurement, vol. 110, pp. 230-238, 2017.
[11] D. Lehocka, J. Klich, J. Foldyna et al., "Copper alloys disintegration using pulsating water jet," Measurement, vol. 82, pp. 375-383, 2016.

[12] Z. Lv, "Study on the erosion mechanism and the processing technology of ultrasonic assisted abrasive waterjet polishing," Doctoral Dissertation, pp. 82-104, Shandong university, Jinan, China, 2015.

[13] Z. Zhongwei, "Study on ultroonic vibration assisted abrasive waterjet cutting," M.S. thesis, Shandong University, Jinan, China, 2014.

[14] J. Foldyna, L. Sitek, B. Svehla, and S. Svehla, "Utilization of ultrasound to enhance high-speed water jet effects," Ultrasonics Sonochemistry, vol. 11, no. 1, pp. 131-137, 2004.

[15] J. Foldyna, L. Sitek, J. Scucka, P. Martinec, J. Valicek, and K. Palenikova, "Effects of pulsating water jet impact on aluminium surface," Journal of Materials Processing Technology, vol. 209, no. 20, pp. 6174-6180, 2009. 


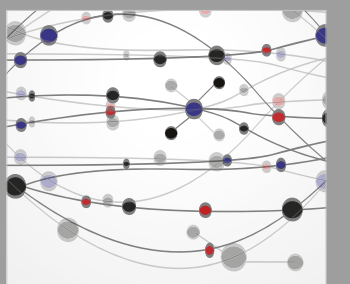

The Scientific World Journal
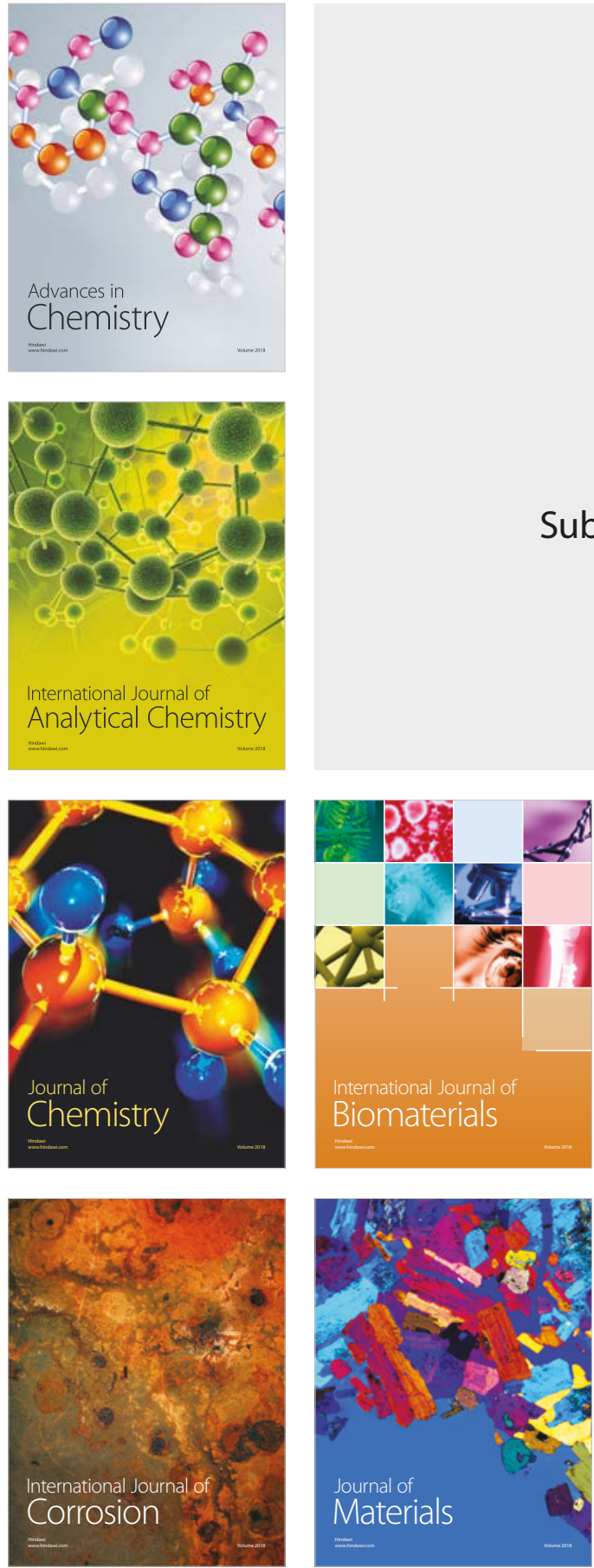

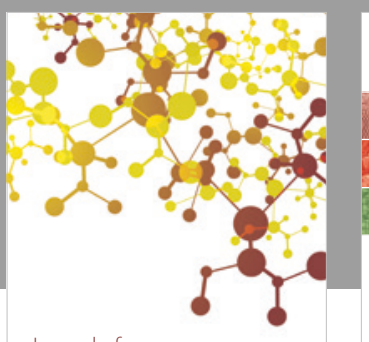

Journal of

Applied Chemistry
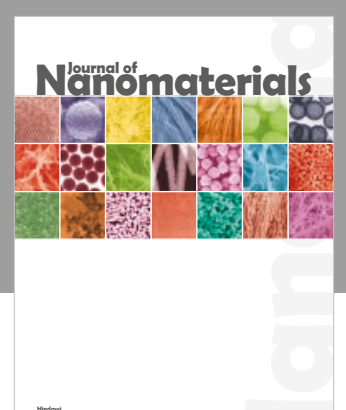

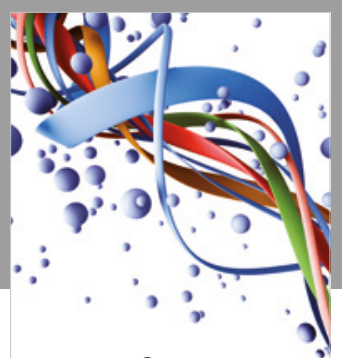

Scientifica

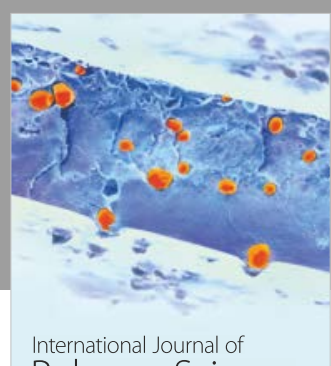

Polymer Science

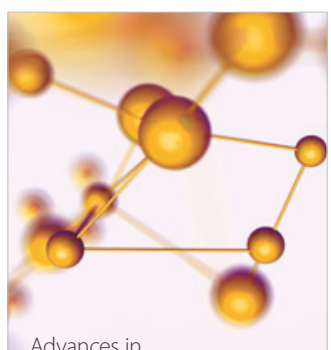

Physical Chemistry
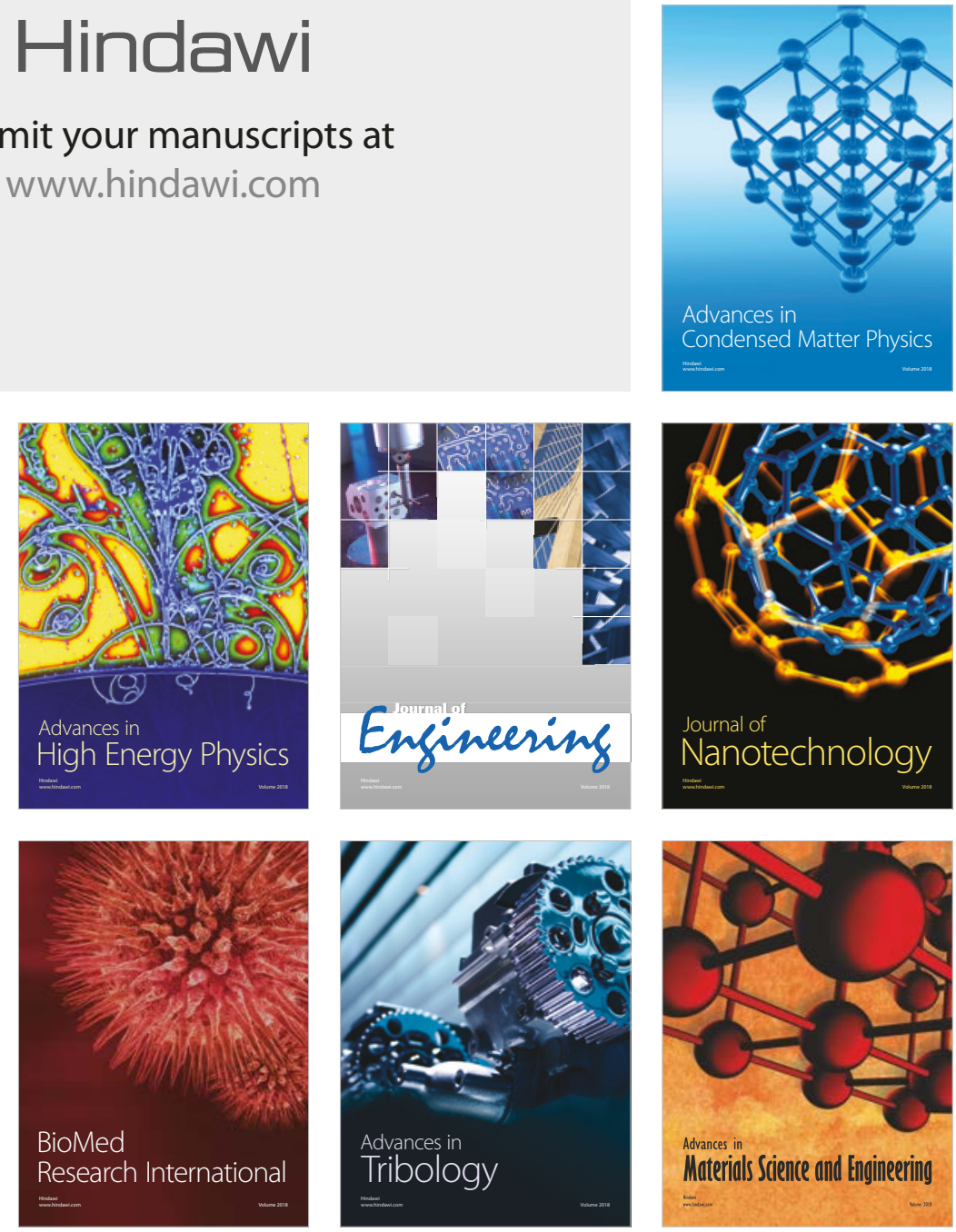